\title{
Integrin and microtubule crosstalk in the regulation of cellular processes
}

\author{
Susan E. LaFlamme ${ }^{1} \cdot$ Shomita Mathew-Steiner ${ }^{1,2} \cdot$ Neetu Singh $^{1} \cdot$ Diane Colello-Borges $^{1} \cdot$ Bethsaida Nieves $^{1}$
}

Received: 25 March 2018 / Revised: 14 August 2018 / Accepted: 27 August 2018 / Published online: 11 September 2018

(c) The Author(s) 2018

\begin{abstract}
Integrins engage components of the extracellular matrix, and in collaboration with other receptors, regulate signaling cascades that impact cell behavior in part by modulating the cell's cytoskeleton. Integrins have long been known to function together with the actin cytoskeleton to promote cell adhesion, migration, and invasion, and with the intermediate filament cytoskeleton to mediate the strong adhesion needed for the maintenance and integrity of epithelial tissues. Recent studies have shed light on the crosstalk between integrin and the microtubule cytoskeleton. Integrins promote microtubule nucleation, growth, and stabilization at the cell cortex, whereas microtubules regulate integrin activity and remodeling of adhesion sites. Integrindependent stabilization of microtubules at the cell cortex is critical to the establishment of apical-basal polarity required for the formation of epithelial tissues. During cell migration, integrin-dependent microtubule stabilization contributes to front-rear polarity, whereas microtubules promote the turnover of integrin-mediated adhesions. This review focuses on this interdependent relationship and its impact on cell behavior and function.
\end{abstract}

Keywords Cell migration $\cdot$ Apical-basal polarity $\cdot$ Adhesion complexes $\cdot$ Focal adhesions

\begin{tabular}{|c|c|}
\hline \multicolumn{2}{|c|}{ Abbreviations } \\
\hline APC & Adenomatous polyposis coli \\
\hline CDK5RAP2 & $\begin{array}{l}\text { Cyclin-dependent kinase 5-related activator } \\
\text { protein } 2\end{array}$ \\
\hline EB1 & End-binding protein-1 \\
\hline ERK & Extracellular signal-regulated kinase \\
\hline CLASP & $\begin{array}{l}\text { Cytoplasmic linker protein (CLIP)-associ- } \\
\text { ated protein }\end{array}$ \\
\hline FAK & Focal adhesion kinase \\
\hline GCP & $\gamma$-tubulin complex protein \\
\hline GSK-3 $\beta$ & Glucogen synthase kinase- $3 \beta$ \\
\hline ILK & Integrin-linked kinase \\
\hline IQGAP & $\begin{array}{l}\text { IQ motif-containing GTPase-activating } \\
\text { protein }\end{array}$ \\
\hline
\end{tabular}

Susan E. LaFlamme

laflams@amc.edu

Shomita Mathew-Steiner

sssteine@iu.edu

1 Department of Regenerative and Cancer Cell Biology, Albany Medical College, 47 New Scotland Avenue, Albany, NY 12208, USA

2 Present Address: Indiana University, 975 W. Walnut Street, Indianapolis, IN 46202, USA

\begin{tabular}{|c|c|}
\hline KANK & $\begin{array}{l}\text { KN motif and ankyrin-repeat-containing } \\
\text { protein }\end{array}$ \\
\hline KIF21A & Kinesin family member $21 \mathrm{~A}$ \\
\hline LL5 $\beta$ & $\begin{array}{l}\text { Pleckstrin homology-like domain family B } \\
\text { member } 2\end{array}$ \\
\hline mDIA & Diaphanous-related formin-1 \\
\hline MMP & Matrix metalloproteinase \\
\hline MOZART & $\begin{array}{l}\text { Mitotic spindle organizing protein associ- } \\
\text { ated with a ring of } \gamma \text {-tubulin }\end{array}$ \\
\hline NEDD1 & $\begin{array}{l}\text { Neural precursor cell expressed, develop- } \\
\text { mentally down-regulated-protein } 1\end{array}$ \\
\hline PAK & p21-activated kinase \\
\hline PAR6 & Partitioning-defective-6 \\
\hline PKC & Protein kinase $\mathrm{C}$ \\
\hline RSK2 & Ribosomal-S6 kinase-2 \\
\hline
\end{tabular}

\section{Introduction}

Integrins form a large family of $\alpha / \beta$ heterodimeric transmembrane receptors that bind to components of the extracellular matrix (ECM) such as fibronectin, collagen, and laminin [1-3]. Integrins function as both adhesion and signaling receptors allowing cells to respond to their ECM environment [1-3]. In collaboration with other receptors, integrins 
activate signal transduction cascades that regulate many cellular activities, including changes in gene expression and cytoskeletal assembly. In doing so, integrins regulate proliferation, survival, and migration at the cellular level, as well as morphogenesis, differentiation, and tissue homeostasis at the level of individual organisms [1-3].

Microtubules are cylinders formed from parallel protofilaments, each of which is composed of a polymer of $\alpha$-tubulin and $\beta$-tubulin heterodimers $[4,5]$. Microtubules can be nucleated at several subcellular sites [6-8] with the $\gamma$-tubulin ring complex ( $\gamma$-TuRC) as the primary catalyst $[7,9,10]$. Microtubules are polarized filaments: their minus ends associate with centrosomes and spindle poles, and their plus ends exhibit dynamic growth and instability $[4,5]$, but can be stabilized by interactions with cellular structures including the cell cortex $[4,11]$. There are many proteins that bind to and regulate microtubule growth, stability, and function; these are often referred to as microtubule-associated proteins or MAPs $[4,5]$.

The microtubule cytoskeleton is essential for many cellular processes [5]. Microtubules provide roadways for vesicular trafficking, as well as the positioning of intracellular organelles. They play essential roles in the establishment of front-rear polarity, which is necessary for directed cell migration [12], and contribute to the establishment of apical-basal polarity that is critical to the function of many different epithelial tissues [13, 14]. Microtubules are also the major structural components of the mitotic spindle, which together with microtubule motors mediate chromosome segregation at mitosis $[15,16]$. This review will discuss the contribution of integrins to the mechanisms regulating microtubule nucleation at the centrosome and microtubule stabilization at the cell cortex both during cell migration and the establishment of apical-basal polarity, as well as the current understanding of how the assembly and turnover of integrin-mediated adhesions is regulated by changes in the microtubule cytoskeleton.

\section{Integrin signaling microtubule nucleation}

Integrin-mediated adhesion initially impacts the microtubule cytoskeleton during the process of microtubule nucleation [17]. Microtubules can be nucleated from centrosomes and spindle poles, Golgi and nuclear membranes, as well as spindle microtubules, and chromatin $[6,7,18]$. The relative usage of these sites is regulated in a cell cycle- and cell type-dependent manner $[8,19,20]$. Microtubules are mostly nucleated by the $\gamma$-TuRC, which contains $\gamma$-tubulin and several associated proteins referred to as $\gamma$-tubulin complex proteins (GCPs). During nucleation, tubulin heterodimers bind to each other and $\gamma$-TuRC [7, 10, 21, 22]. Structurally, $\gamma$-TuRC positions $\gamma$-tubulin to nucleate the 13 protofilaments of a microtubule and caps the base (minus end) of each the newly polymerized microtubule [7, 10, 21, 22].

Studies from our laboratory identified a role for integrin signaling in the regulation of microtubule nucleation from interphase centrosomes. Cells adhered by a signalingdefective, mutant integrin exhibited defects in microtubule regrowth following nocodazole washout [23]. Later studies indicated that defects in microtubule regrowth were due to the suppression of microtubule nucleation [17]. Live-cell imaging demonstrated that the rate at which newly nucleated microtubules emanated from the centrosome was decreased in cells adhered by signaling-defective integrins [17]. Interestingly, the defect in microtubule nucleation correlated with a reduction in the recruitment of $\gamma$-tubulin to the centrosome, suggesting a mechanistic basis for the defect in microtubule nucleation.

Importantly, $\gamma$-tubulin is recruited to the centrosome as part of $\gamma$-TuRC. Thus, integrins may regulate the activation of specific signaling pathways that impact the assembly or recruitment and possibly the activity of $\gamma$-TuRC. Our signaling-defective mutant integrin inhibits the activation of the cytoplasmic tyrosine kinases FAK and Src, as well as the extracellular signal-regulated kinase, ERK [17, 24]. The roles of Src and ERK in regulating microtubule nucleation were further supported by inhibitor studies and molecular genetic approaches. Pharmacological inhibition of either Src or ERK for just 15 min resulted in rapid decline in $\gamma$-tubulin recruitment and microtubule nucleation when cells were adhered by wild-type integrins [17, 25], whereas molecular genetic approaches that resulted in the constitutive activation of Src or ERK restored the recruitment of $\gamma$-tubulin to the centrosome, as well as microtubule nucleation in cells adhered by mutant integrins $[17,25]$.

The targets of integrin signaling that regulate $\gamma$-tubulin localization and microtubule nucleation have not yet been identified. It is important to note that $\gamma$-TuRC is assembled in the cytoplasm where it binds to several proteins that regulate its localization and nucleating activity. These include the following: NEDD1/GCP-WD) [26, 27], CDK5RAP2/ CEP215 [28-30], and MOZART [31, 32]. The association of NEDD1/GCP-WD with $\gamma$-TuRC is required for the centrosomal recruitment of $\gamma$-TuRC and microtubule nucleation in many mammalian cell lines (Fig. 1) [26, 27]. The protein CDK5RAP2 activates the microtubule nucleating ability of $\gamma$-TuRC, presumably by inducing an "activated" conformation of $\gamma$-TuRC (Fig. 1) [10, 33-36]. MOZART (MZT) proteins associate with $\gamma$-TuRC and facilitate the interactions of NEDD1/GCP-WD and CDK5RAP2 with $\gamma$-TuRC $[37,38]$. Thus, integrin signaling may impact $\gamma$-TuRC assembly, the binding of NEDD1/GCP-WD and MOZART, or the nucleating promoting activity of CDK5RAP2. 
Fig. 1 Regulation of microtubule nucleation by integrins. The integrin-dependent activation of SRC and ERK regulates microtubule (MT) nucleation at least in part by regulating the localization of $\gamma$-tubulin to the centrosome. $\gamma$-TuRC is assembled in the cytoplasm where it associates with additional proteins that regulate its centrosomal localization and microtubule nucleating ability. The integrin regulation of microtubule nucleation through SRC-ERK signaling could be due to integrin regulation of the assembly of the $\gamma$-TuRC complex, the association of this complex with NEDD1, CDK5RAP2 or MOZART (MZT) or the binding of the complex to the centrosome (dashed arrows). PM plasma membrane

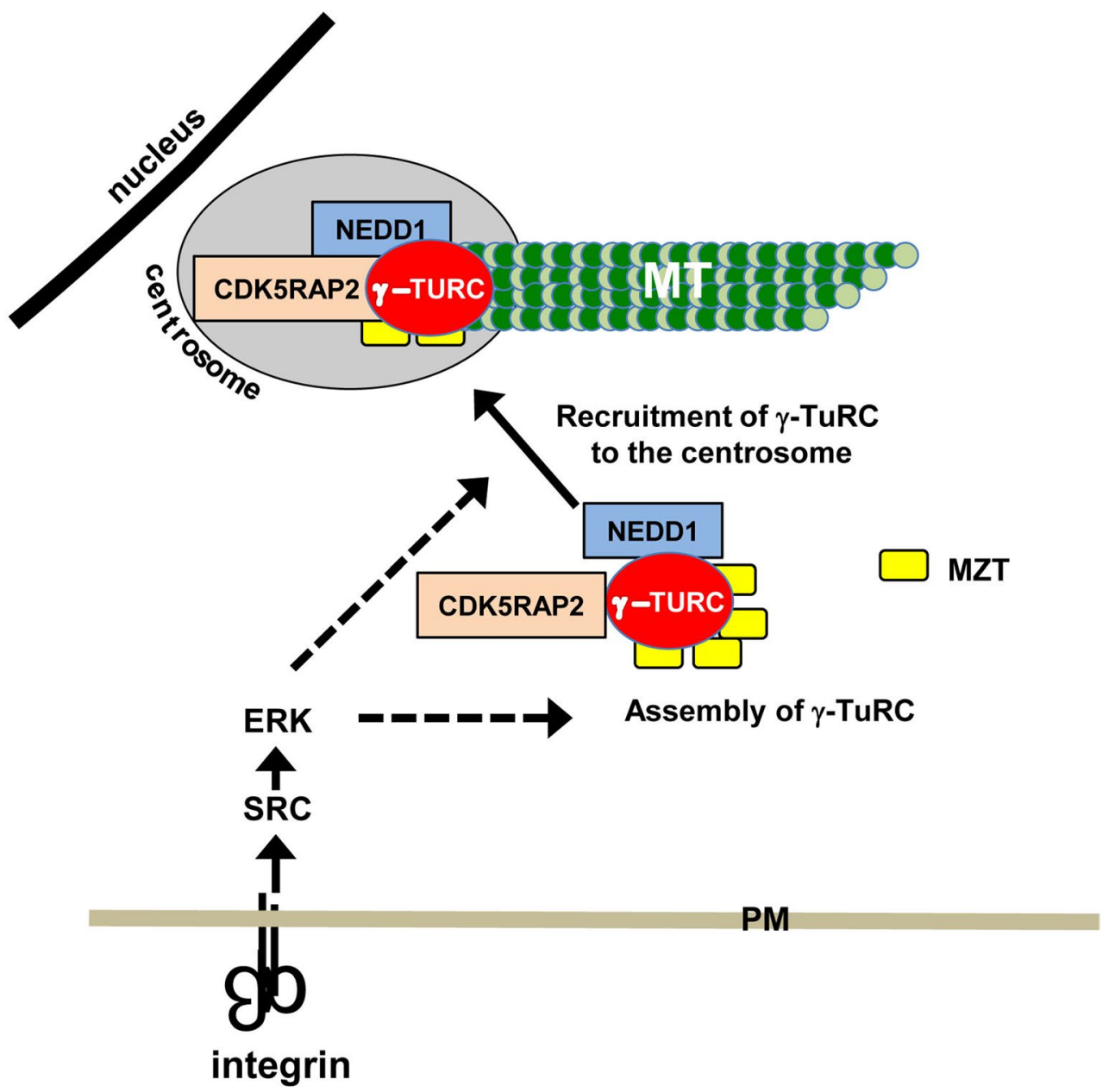

\section{Integrin-regulated microtubule growth and stability}

Microtubule growth and stabilization are regulated by a complex network of proteins that bind at the plus end of microtubules often referred to as microtubule plus-end tracking proteins or +TIPS [4, 39]. Members of this group include the XMAP215 family of microtubule polymerases that promote microtubule growth by binding to plus ends and increasing the rate of tubulin addition by recruiting tubulin dimers [4, 39]. The end-binding (EB) proteins, including EB1 and EB3, are often used to track the plus end of growing microtubules. These proteins also serve as adaptors for the binding of other +TIPs, such as the cytoplasmic linker protein (CLIP)-associated proteins (CLASPs), and adenomatous polyposis coli (APC) [4, 39]. APC, EBs and CLASPs promote microtubule stabilization by linking the plus ends of microtubules to the cell cortex as discussed below.

The growth and stable interaction of microtubules with the cell cortex is a critical contributor to front-back cell polarity that is necessary for directed cell migration [12]. The family of small Rho-GTPases, Rho, Rac and Cdc42, are important regulators of microtubule growth and stabilization [40-46] and are activated downstream of integrin engagement [47-49]. Notably, integrin-dependent signaling is known to promote the stabilization of microtubules at the leading edge of migrating cells $[45,46,50]$. Depriving fibroblasts of integrin-mediated adhesion either by incubating them in suspension or by adhering them to a non-integrin ligand prevented the formation of stable microtubules [50]. Integrin-mediated adhesion activates FAK, and in fibroblasts, integrin-FAK signaling is required for microtubule stabilization, as FAK-null fibroblasts do not stabilize microtubules [50]. The Rho-dependent activation of the formin, mDia, contributes to the formation of a microtubule-stabilizing complex containing EB1, APC and IQGAP [41, 42, $44,50]$, whereas integrin-FAK signaling restricts microtubule stabilization to the leading edge of migrating cells [50]. Interestingly, a similar link between integrins, mDia, IQGAP and microtubule stabilization occurs in mouse keratinocytes [51].

Signaling pathways can also promote microtubule stabilization by inhibiting the activity of proteins that destabilize microtubules. Stathmin is a microtubule-destabilizing 
protein [52]. The activity of stathmin is inhibited by phosphorylation at many sites by several different kinases, several of which are activated in an integrin-dependent manner, including p21-activated kinase (PAK), and ribosomal-S6 kinase-2 (RSK2) [52-54].

The glucogen synthase kinase $3 \beta$ (GSK3 $\beta$ ) is also a negative regulator of microtubule stabilization [12]. GSK3 $\beta$ phosphorylates several MAPs preventing their ability to bind to microtubules, including APC and CLASPs that stabilize microtubules at the cell cortex [55]. Importantly, the activity of GSK3 $\beta$ is suppressed at the leading edge of migrating cells, which allows these MAPs to bind and stabilize microtubules at the cell cortex [56]. Our studies showed that integrin-mediated adhesion of epithelial cells inhibits the activity of GSK $3 \beta$ through the activation of ribosomal S6 kinase RSK [60], whereas suppressing integrin activity leads to the inhibition of FAK and RSK, as well as a decrease in the number of EB1-positive microtubules at the cell surface [24, 57]. In fibroblasts, the Rho-mDia pathway inhibits GSK3 $\beta$ through the activation of a novel PKC [58]. Integrin activation of $\mathrm{Cdc} 42$ in astrocytes also leads to the inactivation of GSK3 $\beta$, but does so via Par6 and the novel PKC, PKC $\zeta[45,46]$. Thus, multiple pathways downstream of integrins in several cell types inhibit GSK3 $\beta$ to promote microtubule stabilization. Additionally, proteomic analysis of complexes associated with activated integrins indicates that these complexes are enriched for proteins associated with microtubule stabilization at the cell cortex including, EB1, IQGAP, mDia, CLASPs, and LL5 $\alpha$, (similar to LL $5 \beta$, further supporting the role of integrins in microtubule stabilization [59]. The role of CLASPs and LL5 $\beta$ in integrin-regulated microtubule stabilization is discussed in more detail below.

\section{Integrins, microtubule stability, and apical- basal cell polarity}

In epithelial tissues, noncentrosomal microtubules align along the apical-basal axis, with their plus ends captured and stabilized at the cell cortex apposed to the basement membrane [60]. Current evidence indicates that integrins play a necessary role in this process. Two recent studies employed mammary epithelial cells as a model to examine the mechanisms by which integrins establish the stable association of microtubule plus ends with the basal cell cortex $[14,61]$. LL5 $\beta$ (and to a lesser extent LL5 $\alpha$ ), CLASP and EB1 were identified as key players in this process. In the human mammary epithelial cell line, MCF10A, as in other epithelial cells, integrins engage laminins in the basement membrane. LL5 $\beta$ and the laminin-binding integrin $\alpha 3 \beta 1$ colocalize at the basal cell cortex. Their basal localization is interdependent: inhibiting the expression of one suppresses the localization of the other [61]. Furthermore, integrin $\alpha 3 \beta 1$ and LL5 $\beta$ can be co-precipitated from cell lysates suggesting that they form a functional complex. The ability of $\alpha 3 \beta 1$ to form a complex with LL5 $\beta$ and to promote the localization LL5 $\beta$ to the basal cortex indicates that integrins stabilize the plus ends of microtubules at the basal cell cortex through a laminin- $\alpha 3 \beta 1-L L 5 \beta-$ CLASP-EB1-microtubule linkage
Fig. 2 Integrins promote the stabilization of microtubules at the basal surface of polarized epithelial cells. Integrins stabilize microtubules at the basal cell cortex through two distinct protein complexes. a Microtubules bind to EB1, which binds to CLASP, which in turn binds to LL5 $\beta$. LL5 $\beta$ is known to be present in a complex with $\alpha 3 \beta 1$ integrins; however, protein interactions (dotted line) mediating this association have not been identified. b Microtubules can also be associated with integrins through ILK, which is a cytoskeleton adaptor and integrin $\beta$ subunit cytoplasmic domain-binding protein. ILK plays a role in stabilizing microtubules at the basal cell surface through a microtubule-EB1mDia-IQGAP-ILK-integrin linkage

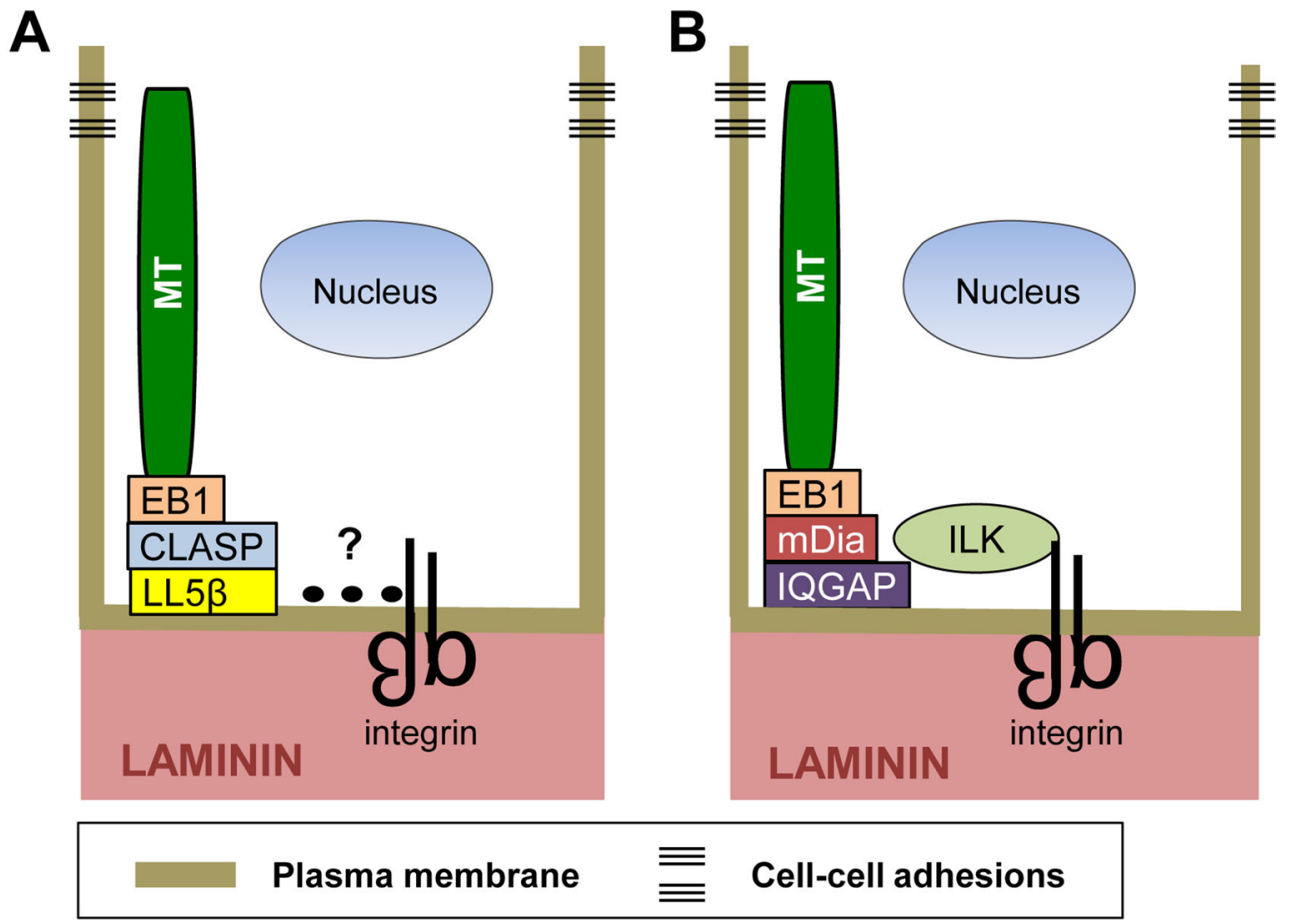


(Fig. 2a). However, there is no evidence to support the idea that $\alpha 3 \beta 1$ and LL5 $\beta$ directly interact with each other. It is possible that proteins involved in this linkage are similar to those found in migrating cells (discussed below).

Other studies have also demonstrated that integrins organize and stabilize the plus ends of microtubules at the basal surface of epithelial cells, which is necessary for epithelial polarity and lumen formation [13]. One study used primary luminal mammary epithelial cells (MECs) from transgenic mice, in which the integrin $\beta 1$ gene was deleted [14]. Interestingly, MECs lacking $\beta 1$ integrins are unable to form acini-containing lumens in $3 \mathrm{D}$ culture. In the absence of $\beta 1$ integrins, EB1-labeled microtubules fail to localize to the basal cell surface. This is consistent with previous proteomic studies described above indicating that EB1 is present in complexes with activated integrins [59], as well as data from a proximal ligation assay demonstrating that $\beta 1$ integrins and EB1 are closely associated at the basal surface [14]. Consistent with these findings, the inhibition of EB1 by RNAi technology also disrupts the establishment of epithelial polarity and the formation of lumens [14].

Many studies have shown that the cytoplasmic domain of the integrin $\beta 1$ subunit can bind to cytoplasmic proteins to link integrins with the cell's cytoskeleton and specific signaling pathways [62]. The integrin-linked kinase (ILK) is one such protein [63, 64]. Interestingly, the deletion of the ILK gene in MEFs also results in defects in the formation of acini in 3D culture similar to that which occurs when $\beta 1$ integrins are deleted, suggesting that integrin-ILK linkages contribute to microtubule stabilization (Fig. 2b) [14]. The stabilization of microtubule plus ends at the basal cell surface promotes directed vesicular transport, which reinforces apical-basolateral polarity and promotes lumen formation [65]. Studies by others indicate that ILK can stabilize microtubules at the cell surface of keratinocytes by recruiting the scaffolding protein IQGAP and one of its effectors, mDia [51], previously shown to stabilize microtubules downstream of integrin engagement (Fig. 2b) [50].

\section{Microtubules regulate adhesion site assembly and turnover during cell migration}

Focal adhesions are well-characterized sites where integrins engage components of the extracellular matrix to provide traction needed for cell movement and platforms for the assembly and activation of signaling complexes that regulate many aspects of cell behavior including cell migration $[66,67]$. The formation of focal adhesions can be triggered by the depolymerimerization of microtubules, which activate tyrosine phosphorylation and the Rho GTPase, leading to enhanced integrin activation, the recruitment of specific adhesion complex components, and the assembly of focal adhesions [68-70].

The turnover or disassembly of focal adhesions to release integrin-matrix interactions is equally important for cell migration. Microtubules are critical to this process; their role was first described two decades ago when the repeated targeting of focal adhesions by microtubules was shown to trigger focal adhesion disassembly [71]. Interestingly, later studies showed that microtubule targeting of focal adhesions did not result in their disassembly in FAK-null fibroblasts, indicating that FAK plays a central role in focal adhesion turnover [72]. Dynamin and clathrin were also identified as key players, suggesting that the endocytosis of integrins may contribute to focal adhesion turnover [72, 73]. Interestingly, FAK binds to and recruits dynamin to focal adhesions; thus, FAK contributes to the positioning of the machinery necessary for the internalization of adhesion site components that accompanies adhesion site disassembly [72]. This is further supported by the finding that clathrin-dependent endocytosis of integrins coincides with focal adhesion disassembly with clathrin accumulating at focal adhesions during the initial stages of microtubule-induced focal adhesion turnover [73].

Microtubule stabilization at sites neighboring focal adhesions also contributes to adhesion site turnover. The disassembly of adhesion sites and the endocytosis of integrins require the disruption of the strong transmembrane linkage mediated by integrins between the actin cytoskeleton and the extracellular matrix. Current data suggest that the microtubule-dependent delivery and the subsequent secretion of matrix metalloproteases (MMPs) contribute to this process [74]. The localization of microtubule-associated CLASPs adjacent to focal adhesions has been temporally correlated with focal adhesion disassembly [74]. In migrating keratinocytes, a central role for CLASP-LL5 $\beta$ interactions has been identified in this process. LL5 $\beta$ (LL5 $\alpha$ in some cells) is a cytoplasmic protein that associates with the cell cortex through the interaction of its Pleckstrin homology $(\mathrm{PH})$ domain with the phospholipid, PI $(3,4,5) \mathrm{P} 3$ [75]. Importantly, LL5 $\beta$ can also bind CLASP, which in turn associates with EB1 bound to the plus end of growing microtubules. This association of LL5 $\beta$, CLASP, and EB 1 provides one mechanism linking the plus ends of microtubules to the cell cortex [76]. The role of these proteins in promoting focal adhesion turnover is further supported by the findings that the inhibition of CLASPs or LL5 $\beta$ using RNAi technology or the pharmacological inhibition of MMP activity prevents the turnover or focal adhesions in migrating keratinocytes [74].

The scaffolding proteins, liprins [77, 78], ELKs [79, 80] and KANKs [81], together with the kinesin family member, KIF21A [82], function together with EB1, CLASPs and LL5 $\beta$ to link microtubules to plasma membrane sites bordering focal adhesions (Fig. 3) [76, 82-84]. These sites have 
Fig. 3 Microtubule-integrin crosstalk in migrating cells. Microtubules are stabilized at the rim of focal adhesions but are also thought to target focal adhesions directly to trigger adhesion site disassembly. Microtubules that are stabilized at the rim of focal adhesions deliver proteins including matrix metalloproteases (MMPs) for secretion to promote focal adhesion turnover. The proteins involved in this stabilization include EB1, CLASP, LL5 $\beta$ and a protein complex containing ELKS and liprins that link the plus ends of microtubules to KANK. Talin provides the linkage between KANK and integrins

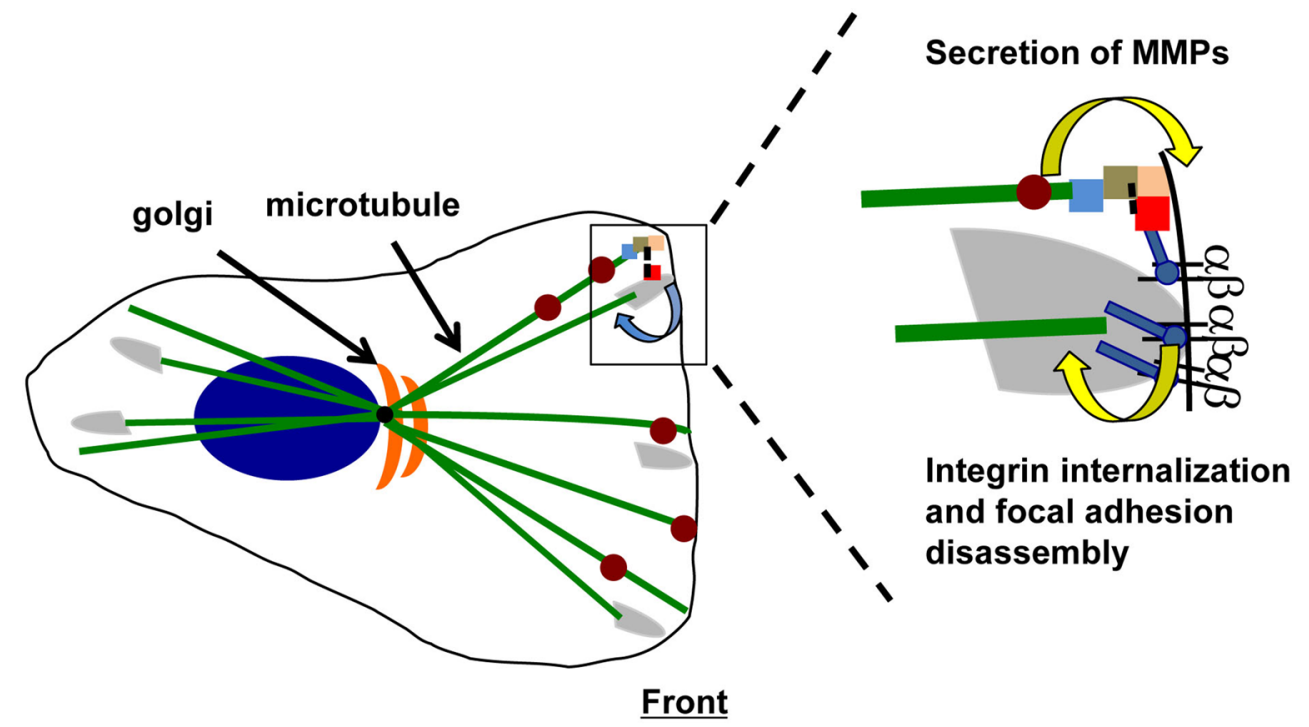

been referred to as cortical microtubule stabilization complexes (CMSCs) [84] and plasma membrane-associated platforms (PMAPs) [77, 83]. Interestingly, protein complexes that co-purify with activated integrin complexes contain microtubule-associated proteins, including EB1 and liprins, implicating activated integrins in the formation of CMSCs and PMAPs [59]. KANKs have been identified as critical players in the recruitment of CLASPs, LL5 $\beta$ and liprins to the rim of focal adhesions [84] and provide a mechanism linking CMSCs to integrins. Specifically, KANKs bind to talin, a cytoskeletal and focal adhesion protein that interacts with the $\beta$ subunit cytoplasmic domains of integrins [1-3]. Thus, the KANK-talin-integrin association provides a mechanism to link microtubules and plasma membraneassociated complexes to integrin-mediated adhesions in migrating cells.

\section{Summary}

The crosstalk between integrins and microtubules regulates cellular processes including directed cell migration, as well as the generation of epithelial apical-basal polarity and lumen formation during the morphogenesis of epithelial tissues. Integrins affect the microtubule cytoskeleton by promoting microtubule nucleation, growth, and stabilization, whereas microtubules impact integrin function by targeting integrin adhesions to promote their turnover. Although much has been learned about the mechanisms involved, interesting questions remain. For example, what are the protein targets of integrin signaling that promote the centrosomal recruitment of $\gamma$-tubulin and microtubule nucleation? NEDD1/ GCP-WD, MOZART and CDK5RAP2 are intriguing candidates. Integrins promote the capture and stabilization of microtubules at cell cortex. Two distinct protein complexes have been characterized. Understanding whether these complexes function in the same cell or whether their assembly and function is context dependent is an important question that has yet to be addressed.

Acknowledgements The authors would like to thank Dr. Michelle Lennartz for her helpful comments during the preparation of this manuscript.

Funding This work was supported by the National Institutes of Health (Grant number GM51540 to SEL).

Open Access This article is distributed under the terms of the Creative Commons Attribution 4.0 International License (http://creativeco mmons.org/licenses/by/4.0/), which permits unrestricted use, distribution, and reproduction in any medium, provided you give appropriate credit to the original author(s) and the source, provide a link to the Creative Commons license, and indicate if changes were made. 


\section{References}

1. Hynes RO (2002) Integrins: bidirectional, allosteric signaling machines. Cell 110:673-687

2. Danen EH, Sonnenberg A (2003) Integrins in regulation of tissue development and function. J Pathol 201:632-641

3. Streuli CH, Akhtar N (2009) Signal co-operation between integrins and other receptor systems. Biochem J 418:491-506

4. Akhmanova A, Steinmetz MO (2015) Control of microtubule organization and dynamics: two ends in the limelight. Nat Rev Mol Cell Biol 16:711-726

5. Alfaro-Aco R, Petry S (2015) Building the microtubule cytoskeleton piece by piece. J Biol Chem 290:17154-17162

6. Zhu X, Kaverina I (2013) Golgi as an MTOC: making microtubules for its own good. Histochem Cell Biol 140:361-367

7. Petry S, Vale RD (2015) Microtubule nucleation at the centrosome and beyond. Nat Cell Biol 17:1089-1093

8. Sanchez AD, Feldman JL (2016) Microtubule-organizing centers: from the centrosome to non-centrosomal sites. Curr Opin Cell Biol 44:93-101

9. Oakley BR, Paolillo V, Zheng Y (2015) Gamma-Tubulin complexes in microtubule nucleation and beyond. Mol Biol Cell 26:2957-2962

10. Kollman JM, Merdes A, Mourey L, Agard DA (2011) Microtubule nucleation by gamma-tubulin complexes. Nat Rev Mol Cell Biol 12:709-721

11. Gundersen GG, Gomes ER, Wen Y (2004) Cortical control of microtubule stability and polarization. Curr Opin Cell Biol $16: 106-112$

12. Etienne-Manneville S (2013) Microtubules in cell migration. Annu Rev Cell Dev Biol 29:471-499

13. Lee JL, Streuli CH (2014) Integrins and epithelial cell polarity. J Cell Sci 127:3217-3225

14. Akhtar N, Streuli CH (2013) An integrin-ILK-microtubule network orients cell polarity and lumen formation in glandular epithelium. Nat Cell Biol 15:17-27

15. Gadde S, Heald R (2004) Mechanisms and molecules of the mitotic spindle. Curr Biol 14:R797-R805

16. Heald R, Khodjakov A (2015) Thirty years of search and capture: the complex simplicity of mitotic spindle assembly. J Cell Biol 211:1103-1111

17. Colello D, Mathew S, Ward R, Pumiglia K, LaFlamme SE (2012) Integrins regulate microtubule nucleating activity of centrosome through mitogen-activated protein kinase/extracellular signal-regulated kinase kinase/extracellular signal-regulated kinase (MEK/ ERK) signaling. J Biol Chem 287:2520-2530

18. Sanders AA, Kaverina I (2015) Nucleation and dynamics of golgiderived microtubules. Front Neurosci 9:431

19. Meunier S, Vernos I (2016) Acentrosomal microtubule assembly in mitosis: the where, when, and how. Trends Cell Biol 26:80-87

20. Maia AR, Zhu X, Miller P, Gu G, Maiato H, Kaverina I (2013) Modulation of Golgi-associated microtubule nucleation throughout the cell cycle. Cytoskeleton (Hoboken) 70:32-43

21. Teixido-Travesa N, Roig J, Luders J (2012) The where, when and how of microtubule nucleation - one ring to rule them all. J Cell Sci 125:4445-4456

22. Lin TC, Neuner A, Schiebel E (2015) Targeting of gamma-tubulin complexes to microtubule organizing centers: conservation and divergence. Trends Cell Biol 25:296-307

23. Reverte CG, Benware A, Jones CW, LaFlamme SE (2006) Perturbing integrin function inhibits microtubule growth from centrosomes, spindle assembly, and cytokinesis. J Cell Biol $174: 491-497$

24. Nieves B, Jones CW, Ward R, Ohta Y, Reverte CG, LaFlamme SE (2010) The NPIY motif in the integrin beta1 tail dictates the requirement for talin-1 in outside-in signaling. J Cell Sci 123:1216-1226

25. Colello D, Reverte CG, Ward R, Jones CW, Magidson V, Khodjakov A, LaFlamme SE (2010) Androgen and Src signaling regulate centrosome activity. J Cell Sci 123:2094-2102

26. Haren L, Remy MH, Bazin I, Callebaut I, Wright M, Merdes A (2006) NEDD1-dependent recruitment of the gamma-tubulin ring complex to the centrosome is necessary for centriole duplication and spindle assembly. J Cell Biol 172:505-515

27. Luders J, Patel UK, Stearns T (2006) GCP-WD is a gammatubulin targeting factor required for centrosomal and chromatinmediated microtubule nucleation. Nat Cell Biol 8:137-147

28. Ching YP, Qi Z, Wang JH (2000) Cloning of three novel neuronal Cdk5 activator binding proteins. Gene 242:285-294

29. Andersen JS, Wilkinson CJ, Mayor T, Mortensen P, Nigg EA, Mann M (2003) Proteomic characterization of the human centrosome by protein correlation profiling. Nature 426:570-574

30. Bond J, Roberts E, Springell K, Lizarraga SB, Scott S, Higgins J, Hampshire DJ, Morrison EE, Leal GF, Silva EO, Costa SM, Baralle D, Raponi M, Karbani G, Rashid Y, Jafri H, Bennett C, Corry P, Walsh CA, Woods CG (2005) A centrosomal mechanism involving CDK5RAP2 and CENPJ controls brain size. Nat Genet 37:353-355

31. Hutchins JR, Toyoda Y, Hegemann B, Poser I, Heriche JK, Sykora MM, Augsburg M, Hudecz O, Buschhorn BA, Bulkescher J, Conrad C, Comartin D, Schleiffer A, Sarov M, Pozniakovsky A, Slabicki MM, Schloissnig S, Steinmacher I, Leuschner M, Ssykor A, Lawo S, Pelletier L, Stark H, Nasmyth K, Ellenberg J, Durbin R, Buchholz F, Mechtler K, Hyman AA, Peters JM (2010) Systematic analysis of human protein complexes identifies chromosome segregation proteins. Science 328:593-599

32. Teixido-Travesa N, Villen J, Lacasa C, Bertran MT, Archinti M, Gygi SP, Caelles C, Roig J, Luders J (2010) The gammaTuRC revisited: a comparative analysis of interphase and mitotic human gammaTuRC redefines the set of core components and identifies the novel subunit GCP8. Mol Biol Cell 21:3963-3972

33. Fong KW, Choi YK, Rattner JB, Qi RZ (2008) CDK5RAP2 is a pericentriolar protein that functions in centrosomal attachment of the gamma-tubulin ring complex. Mol Biol Cell 19:115-125

34. Choi YK, Liu P, Sze SK, Dai C, Qi RZ (2010) CDK5RAP2 stimulates microtubule nucleation by the gamma-tubulin ring complex. J Cell Biol 191:1089-1095

35. Muroyama A, Seldin L, Lechler T (2016) Divergent regulation of functionally distinct gamma-tubulin complexes during differentiation. J Cell Biol 213:679-692

36. Kollman JM, Greenberg CH, Li S, Moritz M, Zelter A, Fong KK, Fernandez JJ, Sali A, Kilmartin J, Davis TN, Agard DA (2015) Ring closure activates yeast gammaTuRC for species-specific microtubule nucleation. Nat Struct Mol Biol 22:132-137

37. Cota RR, Teixido-Travesa N, Ezquerra A, Eibes S, Lacasa C, Roig J, Luders J (2017) MZT1 regulates microtubule nucleation by linking gammaTuRC assembly to adapter-mediated targeting and activation. J Cell Sci 130:406-419

38. Lin TC, Neuner A, Flemming D, Liu P, Chinen T, Jakle U, Arkowitz R, Schiebel E (2016) MOZART1 and gamma-tubulin complex receptors are both required to turn gamma-TuSC into an active microtubule nucleation template. J Cell Biol 215:823-840

39. Kumar P, Wittmann T (2012) +TIPs: sxIPping along microtubule ends. Trends Cell Biol 22:418-428

40. Wittmann T, Bokoch GM, Waterman-Storer CM (2003) Regulation of leading edge microtubule and actin dynamics downstream of Rac1. J Cell Biol 161:845-851

41. Wojnacki J, Quassollo G, Marzolo MP, Caceres A (2014) Rho GTPases at the crossroad of signaling networks in mammals: impact of Rho-GTPases on microtubule organization and dynamics. Small GTPases 5:e28430 
42. Wen Y, Eng CH, Schmoranzer J, Cabrera-Poch N, Morris EJ, Chen M, Wallar BJ, Alberts AS, Gundersen GG (2004) EB1 and APC bind to mDia to stabilize microtubules downstream of Rho and promote cell migration. Nat Cell Biol 6:820-830

43. Wittmann T, Bokoch GM, Waterman-Storer CM (2004) Regulation of microtubule destabilizing activity of Op18/stathmin downstream of Rac1. J Biol Chem 279:6196-6203

44. Bartolini F, Andres-Delgado L, Qu X, Nik S, Ramalingam N, Kremer L, Alonso MA, Gundersen GG (2016) An mDia1-INF2 formin activation cascade facilitated by IQGAP1 regulates stable microtubules in migrating cells. Mol Biol Cell 27:1797-1808

45. Etienne-Manneville S, Hall A (2001) Integrin-mediated activation of Cdc 42 controls cell polarity in migrating astrocytes through PKCzeta. Cell 106:489-498

46. Etienne-Manneville S, Hall A (2003) Cdc42 regulates GSK-3beta and adenomatous polyposis coli to control cell polarity. Nature 421:753-756

47. del Pozo MA, Price LS, Alderson NB, Ren XD, Schwartz MA (2000) Adhesion to the extracellular matrix regulates the coupling of the small GTPase Rac to its effector PAK. EMBO J 19:2008-2014

48. Ren XD, Kiosses WB, Schwartz MA (1999) Regulation of the small GTP-binding protein Rho by cell adhesion and the cytoskeleton. EMBO J 18:578-585

49. Price LS, Leng J, Schwartz MA, Bokoch GM (1998) Activation of Rac and Cdc 42 by integrins mediates cell spreading. Mol Biol Cell 9:1863-1871

50. Palazzo AF, Eng CH, Schlaepfer DD, Marcantonio EE, Gundersen GG (2004) Localized stabilization of microtubules by integrin- and FAK-facilitated Rho signaling. Science 303:836-839

51. Wickstrom SA, Lange A, Hess MW, Polleux J, Spatz JP, Kruger M, Pfaller K, Lambacher A, Bloch W, Mann M, Huber LA, Fassler R (2010) Integrin-linked kinase controls microtubule dynamics required for plasma membrane targeting of caveolae. Dev Cell 19:574-588

52. Cassimeris L (2002) The oncoprotein 18/stathmin family of microtubule destabilizers. Curr Opin Cell Biol 14:18-24

53. LaFlamme SE, Nieves B, Colello D, Reverte CG (2008) Integrins as regulators of the mitotic machinery. Curr Opin Cell Biol 20:576-582

54. Alesi GN, Jin L, Li D, Magliocca KR, Kang Y, Chen ZG, Shin DM, Khuri FR, Kang S (2016) RSK2 signals through stathmin to promote microtubule dynamics and tumor metastasis. Oncogene 35:5412-5421

55. Akhmanova A, Steinmetz MO (2008) Tracking the ends: a dynamic protein network controls the fate of microtubule tips. Nat Rev Mol Cell Biol 9:309-322

56. Kumar P, Lyle KS, Gierke S, Matov A, Danuser G, Wittmann T (2009) GSK3beta phosphorylation modulates CLASP-microtubule association and lamella microtubule attachment. J Cell Biol 184:895-908

57. Mathew SS, Nieves B, Sequeira S, Sambandamoorthy S, Pumiglia K, Larsen M, Laflamme SE (2014) Integrins promote cytokinesis through the RSK signaling axis. J Cell Sci 127:534-545

58. Eng CH, Huckaba TM, Gundersen GG (2006) The formin mDia regulates GSK3beta through novel PKCs to promote microtubule stabilization but not MTOC reorientation in migrating fibroblasts. Mol Biol Cell 17:5004-5016

59. Byron A, Askari JA, Humphries JD, Jacquemet G, Koper EJ, Warwood S, Choi CK, Stroud MJ, Chen CS, Knight D, Humphries MJ (2015) A proteomic approach reveals integrin activation statedependent control of microtubule cortical targeting. Nat Commun 6:6135

60. Luders J, Stearns T (2007) Microtubule-organizing centres: a reevaluation. Nat Rev Mol Cell Biol 8:161-167

61. Hotta A, Kawakatsu T, Nakatani T, Sato T, Matsui C, Sukezane T, Akagi T, Hamaji T, Grigoriev I, Akhmanova A, Takai Y, MimoriKiyosue Y (2010) Laminin-based cell adhesion anchors microtubule plus ends to the epithelial cell basal cortex through LL5alpha/beta. J Cell Biol 189:901-917

62. Morse EM, Brahme NN, Calderwood DA (2014) Integrin cytoplasmic tail interactions. Biochemistry 53:810-820

63. Hannigan GE, Leung-Hagesteijn C, Fitz-Gibbon L, Coppolino MG, Radeva G, Filmus J, Bell JC, Dedhar S (1996) Regulation of cell adhesion and anchorage-dependent growth by a new beta 1-integrinlinked protein kinase. Nature 379:91-96

64. Legate KR, Montanez E, Kudlacek O, Fassler R (2006) ILK, PINCH and parvin: the tIPP of integrin signalling. Nat Rev Mol Cell Biol 7:20-31

65. Noordstra I, Akhmanova A (2017) Linking cortical microtubule attachment and exocytosis. F1000Res 6:469

66. Wehrle-Haller B (2012) Structure and function of focal adhesions. Curr Opin Cell Biol 24:116-124

67. Geiger B, Yamada KM (2011) Molecular architecture and function of matrix adhesions. Cold Spring Harb Perspect Biol 3:1-21

68. Zhou X, Li J, Kucik DF (2001) The microtubule cytoskeleton participates in control of beta 2 integrin avidity. $\mathrm{J}$ Biol Chem 276:44762-44769

69. Bershadsky A, Chausovsky A, Becker E, Lyubimova A, Geiger B (1996) Involvement of microtubules in the control of adhesiondependent signal transduction. Curr Biol 6:1279-1289

70. Ng DH, Humphries JD, Byron A, Millon-Fremillon A, Humphries MJ (2014) Microtubule-dependent modulation of adhesion complex composition. PLoS ONE 9:e115213

71. Kaverina I, Krylyshkina O, Small JV (1999) Microtubule targeting of substrate contacts promotes their relaxation and dissociation. $\mathrm{J}$ Cell Biol 146:1033-1044

72. Ezratty EJ, Partridge MA, Gundersen GG (2005) Microtubuleinduced focal adhesion disassembly is mediated by dynamin and focal adhesion kinase. Nat Cell Biol 7:581-590

73. Ezratty EJ, Bertaux C, Marcantonio EE, Gundersen GG (2009) Clathrin mediates integrin endocytosis for focal adhesion disassembly in migrating cells. J Cell Biol 187:733-747

74. Stehbens SJ, Paszek M, Pemble H, Ettinger A, Gierke S, Wittmann T (2014) CLASPs link focal-adhesion-associated microtubule capture to localized exocytosis and adhesion site turnover. Nat Cell Biol 16:561-573

75. Paranavitane V, Coadwell WJ, Eguinoa A, Hawkins PT, Stephens L (2003) LL5beta is a phosphatidylinositol $(3,4,5)$-trisphosphate sensor that can bind the cytoskeletal adaptor, gamma-filamin. J Biol Chem 278:1328-1335

76. Lansbergen G, Grigoriev I, Mimori-Kiyosue Y, Ohtsuka T, Higa S, Kitajima I, Demmers J, Galjart N, Houtsmuller AB, Grosveld F, Akhmanova A (2006) CLASPs attach microtubule plus ends to the cell cortex through a complex with LL5beta. Dev Cell 11:21-32

77. Astro V, Chiaretti S, Magistrati E, Fivaz M, de Curtis I (2014) Liprin-alpha1, ERC1 and LL5 define polarized and dynamic structures that are implicated in cell migration. J Cell Sci 127:3862-3876

78. Astro V, Tonoli D, Chiaretti S, Badanai S, Sala K, Zerial M, de Curtis I (2016) Liprin-alpha1 and ERC1 control cell edge dynamics by promoting focal adhesion turnover. Sci Rep 6:33653

79. Hida Y, Ohtsuka T (2010) CAST and ELKS proteins: structural and functional determinants of the presynaptic active zone. J Biochem 148:131-137

80. Sudhof TC (2012) The presynaptic active zone. Neuron 75:11-25

81. Kakinuma N, Zhu Y, Wang Y, Roy BC, Kiyama R (2009) Kank proteins: structure, functions and diseases. Cell Mol Life Sci 66:2651-2659

82. van der Vaart B, van Riel WE, Doodhi H, Kevenaar JT, Katrukha EA, Gumy L, Bouchet BP, Grigoriev I, Spangler SA, Yu KL, Wulf PS, Wu J, Lansbergen G, van Battum EY, Pasterkamp RJ, MimoriKiyosue Y, Demmers J, Olieric N, Maly IV, Hoogenraad CC, Akhmanova A (2013) CFEOM1-associated kinesin KIF21A is a cortical microtubule growth inhibitor. Dev Cell 27:145-160 
83. Astro V, de Curtis I (2015) Plasma membrane-associated platforms: dynamic scaffolds that organize membrane-associated events. Sci Signal 8:re1

84. Bouchet BP, Gough RE, Ammon YC, van de Willige D, Post H, Jacquemet G, Altelaar AM, Heck AJ, Goult BT, Akhmanova A (2016)
Talin-KANK1 interaction controls the recruitment of cortical microtubule stabilizing complexes to focal adhesions. Elife 5:1-23 